\title{
On "Literature Reviews of, and for, Educational Research": A Response to the Critique by Joseph Maxwell
}

\author{
by David N. Boote and Penny Beile
}

W e thank Joseph Maxwell (this issue of Educational Researcher, pp. 28-31) for accepting our invitation to examine the roles and expectations of dissertation literature reviews. We agree that most are inadequate but disagree why. Maxwell argues that dissertations should emulate research articles and include a conceptual framework that only discusses relevant literature. Candidates need not present a thorough analysis and synthesis of the scholarship and research, Maxwell argues, or justify claims made about the literature. Finally, he asserts that we misunderstand the relationship between literature and research, leading to an accusation of "foundationalism." However, these specific disagreements ignore fundamental differences about the purposes of the doctoral dissertation and the relationship between those purposes and doctoral program goals. In this rejoinder, we briefly explore these conceptual and normative differences.

\section{Research Report or Capstone Achievement?}

While the ostensive purpose of Maxwell's article is to criticize our recommendations for dissertation literature reviews and propose his own, the article reveals fundamental differences. Our recommendations addressed major problems with doctoral programs and the field and enterprise of education. For example, we recommended a comprehensive literature review that justifies knowledge claims about the literature to address several problems: many doctoral graduates have a narrow view of education; the field is marked by a lack of generativity; and naïve educational beliefs and practices persist. By contrast, Maxwell justifies his claims by presuming that the dissertation is only a research report and it is important that candidates learn to report research in accordance with accepted norms. All other goals and problems are of secondary importance. Those who accept that dissertations should be only research reports, and that the norms of research reporting would not be improved by including more sophisticated literature reviews, may be attracted to Maxwell's argument. We believe the argument is inadequate.

As the capstone of the highest academic degree, one traditional purpose of the doctoral dissertation was an opportunity and requirement for the candidate to "display" his or her knowledge of the field. Unfortunately, this once meaningful purpose has become a hollow ritual, and the traditional literature review is "something of an anachronism" (Krathwohl \& Smith, 2005, cited in Maxwell, this issue). But if Maxwell believes we were

Educational Researcher, Vol. 35, No. 9, pp. 32-35 defending the traditional purpose of merely displaying information or including "irrelevant" literature, then we did not make our point clearly.

Instead, we were trying to articulate expectations of a dissertation literature review as a distinct genre of writing, "repurposing" it (Swales, 2004) to align better with the goals of doctoral programs. Austin (2002, p. 4) argues that research on doctoral programs shows a "lack of systematic preparation for the full array of professional responsibilities" and that our assessment strategies should help graduate students develop toward these often implicit program goals. Dissertation assessment criteria provide focal expectations for this developmental trajectory. Rather than hoping candidates will absorb these skills by osmosis, we need to teach them explicitly what we want them to learn, assess the development of these skills throughout their programs, and expect these skills to be demonstrated in their dissertations. Unfortunately, because Maxwell chose not to explain how his recommendations address other program goals, we are uncertain whether he believes these goals are unimportant or that they should not be assessed in the dissertation.

At least four related goals of doctoral programs are not reducible to producing a good research report: understand the research and scholarship in the field; develop intellectual independence; develop information fluency; ${ }^{1}$ and systematically and continually reappraise ideas and practices. We want doctoral candidates to formally understand the literature in their field. Shulman (2002, p. 40) argues that "[i]n contrast to knowledge and information, understanding connotes a form of ownership." Formal knowledge claims require epistemic warrants, which are valued elsewhere in dissertations. We not only expect candidates to detail their data collection and analysis methods, but also to justify and defend their methodological choices. In addition to ensuring that candidates understand the epistemic basis of their knowledge claims, these justifications better enable readers to trust candidates' empirical claims. Although we value epistemic warrants in methodology, candidates (and other researchers) routinely make knowledge claims about the literature without epistemic warrants. Without developing such warrants, candidates are merely borrowing their literature review or conceptual framework. Why should we trust them?

Understanding, in Shulman's sense, implies the other three goals. The ability to develop and defend epistemic warrants about the literature enables candidates to develop intellectual independence. Someone with a doctorate ought to be able to make a reasonable range of intellectual decisions, including what to include 
and how to present his or her dissertation, in consultation with a supervisor and committee. Making such decisions, in turn, requires candidates purposefully to find, evaluate, analyze, and synthesize that literature - the skills and knowledge of information fluency. Finally, it is not enough for a publication to sit on a library shelf or on a server. Educationists must read it, discuss it, and continually re-evaluate it to understand it: "there can be no knowledge without a knower. Knowledge does not exist . . . in an abstract sense" (Shera, 1970, quoted in Budd, 2004). Every member of an academic and professional community is obliged to engage in this difficult work. Without such ongoing engagement with the literature, we are neither an academic nor a professional community.

If we value understanding, intellectual independence, information fluency, and ongoing reappraisal in our doctoral programs, as we should, we should also expect these skills to be demonstrated in our dissertations. By contrast, if we take the research article as our exemplar for the dissertation, we must ask whether it requires everything we expect candidates to demonstrate at the end of their terminal degree, and whether the accepted norms of research reporting are adequate for the complexities of educational scholarship. Doctoral program faculty and dissertation supervisors must remember that these choices affect not only individual candidates, but also affect the broader education community.

\section{Research Report or Cultural Tool?}

At several points Maxwell questions our understanding of the relationship between literature and research, most pointedly with the suggestion that we "clearly hold a foundationalist conception of the place and function of literature reviews in research" (p. 30). Unfortunately, Maxwell does not provide a citation or even an explanation of what he means by "foundationalism." We presume that he means the epistemological belief that knowledge claims can only be justified from "foundational" knowledge. The suggestion that our metaphor revealed this epistemological position is baffling. We did suggest the literature review is a foundation of a study, and we agree that this metaphor, like any metaphor, is inadequate to express all aspects of this relationship. We also borrowed Shulman's (1999) notion of generativity to assert that good educational research builds from and learns from prior research and scholarship. We then went on to enumerate several ways that prior research and scholarship can be used to improve a study. Nowhere did we argue or assume that prior research and scholarship provides "foundational" beliefs that provide the only basis to make or judge knowledge claims.

Instead, our analysis and recommendations assumed a social epistemology. We assumed that earning a doctorate is at least as much a social achievement as it is an individual achievement - the graduate earns the honorific "Doctor" and nominally becomes a peer of university faculty. Doctoral programs also socialize students into the practices, values, tools, language, and problems of an academic community. More importantly, however, our arguments assumed that it is useful and important to see that the assembled practices, values, tools, languages, and even the research problems "are themselves culturally and historically situated, carrying the wisdom and hidden assumptions that went into their design.
Thus they form a learning system with the learner, reorganizing action and determining what can be carried out" (Salomon \& Perkins, 1998, p. 5). By engaging in social and communicative practices with the intellectual resources of research and scholarly literatures, the candidate participates in the knowledge construction of those intellectual communities. The dissertation is, or at least ought to be, one of the key cultural artifacts of academic learning, and our expectations of this genre of writing (structure, style, content, and purpose) express our practices and values (Swales, 2004).

In turn, the citations and arguments assembled in a dissertation have the potential to become the "epistemic community" (Knorr Cetina, 1999; Cronin, 2005) of the candidate, creating in his or her mind an ideal audience - the people who are best capable of judging the merits and contributions of a dissertation. For a small percentage of candidates with dissertation committees populated by leading experts, or who actively write for major conferences or journals, their ideal audience approximates their real audience. Their participation in the social life of the profession shapes their thinking and writing. For most, however, the ideal audience is replaced with the real audience of their dissertation committee. Without a clear epistemic community, preexisting or assembled by the candidate, the dissertation becomes a "pseudocommunicative task" (Shaw, 1991) without clear structure, style, content, or purpose. Candidates are trapped between their ideal and real audiences, not understanding what or to whom they should be writing.

A thorough, sophisticated literature review can enable a candidate to transcend the local academic community, as scholars have always used predecessors' writings to transcend personal experience and local community. If candidates often have difficulty transitioning to academic values (Labaree, 2003), then a repurposed literature review may be the ideal cultural tool to enable this transition. Can a conceptual framework that discusses relevant prior publications do this? A myopic focus on the dissertation as a research study, detached from the broader purposes of the doctoral program and academic community, forestalls this potential.

More generally, Fullar's (1988) program of social epistemology encourages us to inquire into the social conditions that must prevail before normative epistemological criteria should apply. Simply, it is unreasonable to have epistemic expectations of someone who is culturally unable to achieve them. If we look, for example, at the epistemic expectation that a dissertation make an original contribution to the literature, we should ask whether doctoral candidates have adequate cultural resources to make an original contribution. The dissertations we have examined lead us to believe that for most candidates the answer is "no." Not only do their literature reviews fail to provide adequate intellectual resources to make an original contribution, they are inadequate even to judge what would constitute an original contribution.

\section{Relevant or Thorough?}

Limiting the dissertation to discussing "relevant" prior studies in a "conceptual framework" and eliminating the hoary label "literature review" are appealing suggestions. Maxwell then suggests several 
criteria of relevance: "contribut[ing] an important concept, finding, or method"; "provid[ing] a necessary piece of the argument that explains and justifies this study"; answering any important potential questions; and explaining the value of the research (p. 29). Unfortunately, this notion of relevance and these criteria, while well intentioned, obfuscate more than they illuminate and add nothing to our analysis.

The criterion of relevance confuses the processes of finding and selecting the literature, the processes of analyzing and synthesizing the selected pieces, and the decisions about rhetorical presentation in the dissertation. Maxwell criticizes us for recommending a thorough literature review, suggesting that candidates need only include "all" relevant literature. This is tautological and amounts to recommending candidates include everything they should include and nothing else. Who would argue to include "irrelevant" literature? Relevance is subjective and contextual, and decisions about relevance must be justified when producing formal knowledge claims. A candidate cannot judge pieces he or she does not know and cannot evaluate their relevance until the candidate understands the whole literature. Thus, in one sense, "relevance" is another way of saying decisions about "criteria for inclusion and exclusion" during the search, and such decisions are ongoing and continually revised as more is learned about what has been written (Foster, 2003). In a second sense, "relevance" is a way of saying decisions made about how to analyze and synthesize the literature. As the candidate better understands the literature, his or her notions of relevance may shift or change entirely. In a third sense, "relevance" is a way of saying decisions about the rhetorical structure of the literature review, which pieces to include, and how to present them. We can see no advantage to reducing these many decisions to a single criterion.

Maxwell's articulation of the relationship between literature and research has at least one additional limitation. Because he limits the discussion of previous literature to those pieces that support and justify a study, there is seemingly no place for critical evaluation of that literature or the study, though he values it nonetheless. Bad ideas and practices are endemic in education: practices that do not work, practices that achieve questionable goals, ideas that confuse, unexamined ideologies, good ideas used inappropriately. Several of our criteria that Maxwell dismissedthoroughness, critical gaps in the literature, situating the literature in its scholarly and historical context, methodological and practical weaknesses-help candidates avoid such "degenerative" research traditions and steer toward productive projects (Lakatos, 1978). A repurposed literature review is an antibiotic that kills the bad ideas that infect education, and the scholarly habits candidates learn help to strengthen our collective immune system.

We appreciate Maxwell's reminder that personal and professional experience can provide what we call a "productive insight," as can ideas and methods borrowed from other literatures. In turn, a "productive insight" can be developed into an integrated set of concepts, theories, and empirical and normative claims gleaned from the literature. Developing such a "conceptual framework" is one useful strategy for critically evaluating and synthesizing the literature, but it cannot replace a thorough review of the literature.

We hope these arguments show why a discussion of relevant literature in a conceptual framework is inadequate. Yet Maxwell's concerns remind us that thoroughness is not itself a virtue, but serves other purposes. Relevance implies intentionality. Like an intentionally chosen rhetorical structure, an intentionally chosen and justified strategy for searching, selecting, evaluating, and synthesizing the literature is (usually ${ }^{2}$ ) not an end unto itself. However, we differ with Maxwell concerning whether the research project is the only purpose served in the dissertation.

\section{Looking Forward}

It is likely that Maxwell will believe that we misunderstood his arguments, just as we think that we were misunderstood at several points. His critique and our rejoinder have explored some of the conceptual and normative issues at play as we attempt to repurpose the dissertation literature review specifically, and dissertations and doctoral programs in education generally. However, these conceptual and normative discussions will be greatly limited if left as abstractions and not examined in empirical studies and substantiated in detailed examples. Such studies and concrete exemplars not only will help us to understand further the roles the literature review can and should play, they will also help students, candidates, and faculty understand what they are working toward.

\section{NOTES}

${ }^{1}$ Although there is ongoing discussion about the differences between "information literacy" and "information fluency," both focus on the ability to find, select, organize, evaluate, analyze, and synthesize a variety of kinds of information, and the ability to use various tools and technologies accomplish these tasks (Association of College and Research Libraries, 2000).

${ }^{2}$ A suitably sophisticated systematic review can serve as a dissertation and too rarely does, as can theory, philosophy, and other scholarly forms of educational inquiry. Many educationists don't do "research," as Maxwell seemingly presumes.

\section{REFERENCES}

Association of College and Research Libraries (2000). Information literacy competency standards for higher education. Retrieved October 8 , 2006, from http http://www.ala.org/ala/acrl/acrlstandards/information literacycompetency.htm

Austin, A. E. (2002, November). Assessing doctoral students' progress along developmental dimensions. Paper presented at the annual meeting of the Association for the Study of Higher Education, Sacramento, CA.

Budd, J. M. (2004). Academic libraries and knowledge: A social epistemology framework. Journal of Academic Librarianship, 30(5), 361-367.

Cronin, B. (2005). The hand of science: Academic writing and its rewards. Lanham, MD: Scarecrow Press, Inc.

Foster, A. (2003). A nonlinear model of information-seeking behavior. Journal of the American Society for Information Science and Technology, 55(3), 228-267.

Fullar, S. (1988). Social epistemology. Bloomington, IN: Indiana University Press.

Knorr Cetina, K. (1999). Epistemic cultures: How the sciences make knowledge. Cambridge, MA: Harvard University Press.

Labaree, D. F. (2003). The peculiar problems of preparing educational researchers. Educational Researcher, 32(1), 13-22.

Lakatos, I. (1978). The methodology of scientific research programmes. Cambridge, MA: Cambridge University Press.

Salomon, G., \& Perkins, D. N. (1998). Individual and social aspects of learning. Review of Research in Education, 23, 1-24.

Shaw, P. (1991). Science research students' composing process. English for Specific Purposes, 10(2), 189-206. 
Shulman, L. S. (1999). Professing educational scholarship. In E. C. Lagemann \& L. S. Shulman (Eds.), Issues in education research: Problems and possibilities (pp. 159-165). San Francisco: Jossey-Bass.

Shulman, L. (2002). Making a difference: A table of learning. Change, 34(6), 36-44.

Swales, J. M. (2004). Research genres: Explorations and applications. Cambridge: Cambridge University Press.

\section{AUTHORS}

DAVID N. BOOTE is an Associate Professor of Curriculum Studies and Coordinator of the Ed.D. program in the College of Education, University of Central Florida, Orlando, FL, 32816-1250; dboote@mail. $u c f . e d u$. His interests include how people learn to do research and solve problems, and how school culture affects curriculum and professional discretion.

PENNY BEILE is an Associate Librarian at the University of Central Florida, P.O. Box 162666, Orlando, FL, 32816-2666; pbeile@mail. $u c f . e d u$. Her research focuses on education students' informationseeking behavior and continued refinement of the construct of information literacy.

Manuscript received August 10, 2006

Revision received October 9, 2006

Accepted October 10, 2006

\section{Erratum}

In the August/September 2006 issue of Educational Researcher, the article "Race, Class, and Disproportionality: Reevaluating the Relationship Between Poverty and Special Education Placement," by Carla O'Connor and Sonia DeLuca Fernandez, contains an incorrect source citation. On page 8, column 2, the second block quotation was accidentally attributed to Griffin and Case (1997). In fact, the quotation is from the National Research Council report (NRC, 2002) that had been quoted immediately above, and it represents the report's interpretation of the findings of Griffin and Case. We regret this error. 